population at high risk for lung cancer. Hopefully, future studies can design and implement efficacious tailored smoking cessation programmes for participants in lung cancer screening programmes. ${ }^{5}$

Competing interests: None.

Thorax 2009;64:371-372. doi:10.1136/thx.2008.111039

\section{REFERENCES}

1. Cox LS, Clark MM, Jett JR, et al. Change in smoking status after spiral chest computed tomography scan screening. Cancer 2003;98:2495-501.

2. Townsend CO, Clark MM, Jett JR, et al. Relation between smoking cessation and receiving results from three annual spiral chest computed tomography scans for lung carcinoma screening. Cancer 2005;103:2154-62.
3. Ashraf $\mathbf{H}$, Tonnesen $\mathrm{P}$, Pedersen $\mathrm{JH}$, et al. Effect of CT screening on smoking habits at 1-year follow-up in the Danish Lung Cancer Screening Trial (DLCST). Thorax 2009;64:388-92

4. Clark MM, Cox LS, Jet JR, et al. Effectiveness of smoking cessation self-help materials in a lung cancer screening population. Lung Cancer 2004;44:13-21.

5. Taylor KL, Cox LS, Zincke N, et al. Lung cancer screening as a teachable moment for smoking cessation. Lung Cancer 2007:56:125-34.

\title{
Sex, cough and (digital) audiotape
}

\section{Peter V Dicpinigaitis}

Cough is among the most common complaints for which medical attention is sought ${ }^{1}$ yet, historically, despite its significance as a health issue worldwide, cough has been under-represented in terms of basic and clinical research efforts aimed at understanding its mechanisms and developing effective therapeutic agents. Thankfully, the past decade has witnessed an emergence of interest in cough within the scientific community. Highlighting the perceived importance of cough as a clinical problem, no less than five major pulmonary societies have published guidelines addressing the management of cough: the European Respiratory Society, ${ }^{2}$ the German Respiratory Society, ${ }^{3}$ the American College of Chest Physicians, ${ }^{4}$ the British Thoracic Society $^{5}$ and the Japanese Respiratory Society. ${ }^{6}$ In addition, a task force of the European Respiratory Society published the first ever guidelines on the assessment of cough, ${ }^{7}$ aimed at promoting and improving the quality of cough-related research. Furthermore, the discovery of several pharmacological receptors relevant to the cough reflex-such as TRPV $1,{ }^{8} \mathrm{NOP} 1^{9}$ and cannabinoid receptors ${ }^{10}$ — has stimulated numerous investigative programmes within the pharmaceutical industry.

Research efforts in cough continue to be hindered by a dearth of clinically relevant, well validated measurement tools. Although cough reflex sensitivity can be accurately and reproducibly determined using inhalational (capsaicin or citric acid) cough challenge methodology, results generated in the laboratory may not correlate with the clinical state. ${ }^{11}$ For example, a potential antitussive agent under investigation may demonstrate the

Correspondence to: Dr P V Dicpinigaitis, Albert Einstein College of Medicine, 1825 Eastchester Road, Bronx, NY10461, USA; pdicpinigaitis@pol.net ability to inhibit experimentally-induced cough but fail to suppress pathological cough. ${ }^{11}$

Subjective cough-specific instruments such as the Leicester Cough Questionnaire $(\mathrm{LCQ})^{12}$ and the Cough-specific Quality of Life Questionnaire (COLO) ${ }^{13}$ have been published, validated and have served as useful tools in clinical cough research. However, factors such as mood, level of vigilance, symptoms associated with cough (pain, vomiting, incontinence, syncope) and placebo effect ${ }^{14}$ may influence an individual's perception of cough severity and frequency, as well as the effect of a pharmacological intervention on these parameters. Indeed, studies have demonstrated that subjective measures of cough are only moderately related to objectively measured cough. ${ }^{15}$ Thus, the optimal use of subjective symptom assessment tools would appear to be in conjunction with objective cough measurement. The ideal objective cough monitor would be a portable, ambulatory, digital-recording device able to store at least $24 \mathrm{~h}$ of information that could then be analysed using software capable of recognising a cough with adequate sensitivity and specificity. Although several objective cough monitoring systems are currently under development, only one is commercially available at present. ${ }^{16}$

In this issue of Thorax, Kelsall and colleagues $^{17}$ employ their objective cough monitoring system (Vitalojak, Vitalograph, UK) to investigate whether, among patients with chronic cough presenting to a tertiary referral clinic, women have higher cough rates than men (see page 393). Furthermore, they examined whether other predictors of objective cough frequency could be discerned.

It is not surprising that women were shown to have significantly higher cough rates, albeit only during the night. Women are consistently over-represented in specialty referral centres. Previous studies have shown that healthy women have a more sensitive cough reflex than that of healthy men. ${ }^{18} 19$ The present study confirms the results of a previous trial of patients with pathological cough, in which women had heightened cough sensitivity compared with men. ${ }^{20}$ Notably, though, in this study sex and cough reflex sensitivity (to citric acid) independently predicted higher cough rates, implying that factors other than cough reflex sensitivity (and still to be identified) may be contributing to a greater amount of coughing in women. The inability of the LCQ to demonstrate a significantly poorer cough-related quality of life in women, despite a much higher cough rate than men, reminds us that a particular subjective instrument may omit information relevant to a particular study population. The ability of the COLO to discern sex-related differences ${ }^{21} 22$ probaby reflects its inclusion of items particularly distressful to women with chronic cough, such as urinary incontinence.

Remarkable in this study is the finding that older subjects had higher cough frequency than younger subjects. There appears to be a presumption in the literature that cough reflex sensitivity is diminished in elderly subjects because patients with a history of aspiration pneumonia, most of whom are elderly, have been shown to have a diminished response to citric acid. ${ }^{23}$ One study specifically evaluated cough reflex sensitivity to citric acid in a group of 110 subjects (60 men; age range 20-78 years) divided into groups from the third to eighth age decades. Cough reflex sensitivity did not differ significantly among the six age decades, suggesting that cough reflex sensitivity does not diminish with age. ${ }^{25}$ Regardless, the authors of the present study found that the relationship between cough frequency and age was independent of cough reflex sensitivity as well as duration of cough. Thus, an explanation for the increased cough frequency in older subjects in this study remains elusive (gastro-oesophageal reflux?), but provides fertile ground for further research. 
Given the significance of cough as a clinical problem worldwide and the paucity of safe and effective antitussive drugs, high-quality investigation in the field of cough remains a priority. The optimal clinical study should include both subjective and objective cough-specific end points, measured in appropriately selected subject populations. The availability of practical, well-validated automated cough monitors will represent a major breakthrough in clinical cough research and is awaited with great anticipation.

Competing interests: None.

Thorax 2009;64:372-373. doi:10.1136/thx.2008.111021

\section{REFERENCES}

1. Burt CW, Schappert SM. Ambulatory care visits to physician offices, hospital outpatient departments, and emergency departments: United States, 19992000. Vital Health Stat 2004;13:1-70.

2. Morice $\mathbf{A H}$, Fontana GA, Sovijarvi AR, et al. The diagnosis and management of chronic cough. Eur Respir J 2004;24:481-92.

3. Kardos P, Cegla U, Gillissen A, et al. The German Respiratory Society's guideline for the diagnosis and treatment of patients with acute and chronic cough (German). Med Klin (Munich) 2004;99:468-75.
4. Irwin RS, Baumann MH, Bolser DC, et al. Diagnosis and management of cough executive summary: ACCP evidence-based clinical practice guidelines. Chest 2006;129(Suppl):1-23S.

5. Morice AH, McGarvey L, Pavord I, et al. British Thoracic Society Cough Guideline Group. Recommendations for the management of cough in adults. Thorax 2006;61 (Suppl 1):i1-24.

6. Kohno S, Ishida T, Uchida Y, et al. The Japanese Respiratory Society guidelines for management of cough. Respirology 2006;11(Suppl 4):S135-86.

7. Morice AH, Fontana GA, Belvisi MG, et al. European Respiratory Society guidelines on the assessment of cough. Eur Respir J 2007;29:1256-76.

8. McLeod RL, Correll CC, Jia Y, et al. TRPV1 antagonists as potential antitussive agents. Lung 2008;186(Suppl 1):S59-65.

9. McLeod RL, Bolser DC, Jia Y, et al. Antitussive effect of nociceptin/orphanin FO in experimental cough models. Pulm Pharmacol Ther 2002;15:213-6.

10. Belvisi MG. Preclinical assessment of novel therapeutics on the cough reflex: cannabinoid agonists as potential antitussives. Lung 2008;186(Suppl 1):S66-9.

11. Dicpinigaitis PV. Experimentally induced cough. Pulm Pharmacol Ther 2007;20:319-24.

12. Birring SS, Prudon B, Carr AJ, et al. Development of a symptom specific health status measure for patients with chronic cough: Leicester Cough Questionnaire (LCQ). Thorax 2003;58:339-43.

13. French CT, Irwin RS, Fletcher KE, et al. Evaluation of a cough-specific quality-of-life questionnaire. Chest 2002;121:1123-31.

14. Eccles R. The powerful placebo in cough studies? Pulm Pharmacol Ther 2002;15:303-8.
15. Decalmer SC, Webster D, Kelsall AA, et al. Chronic cough: how do cough reflex sensitivity and subjective assessments correlate with objective cough counts during ambulatory monitoring? Thorax 2007;62:329-34.

16. Smith J, Woodcock A. New developments in the objective assessment of cough. Lung 2008;186/Suppl 1):S48-54.

17. Kelsall A, Decalmer S, McGuinness K, et al. Sex differences and predictors of objective cough frequency in chronic cough. Thorax 2009;64:391-6.

18. Fujimura M, Kasahara K, Kamio $Y$, et al. Female gender as a determinant of cough threshold to inhaled capsaicin. Eur Respir J 1996;9:1624-6.

19. Dicpinigaitis PV, Rauf K. The influence of gender on cough reflex sensitivity. Chest 1998;113:1319-21.

20. Kastelik JA, Thompson RH, Aziz I, et al. Sex-related differences in cough reflex sensitivity in patients with chronic cough. Am J Respir Crit Care Med 2002;166:961-4.

21. French $\mathbf{C T}$, Fletcher KE, Irwin RS. Gender differences in health-related quality of life in patients complaining of chronic cough. Chest 2004;125:482-8.

22. French $\mathbf{C T}$, Fletcher KE, Irwin RS. A comparison of gender differences in health-related quality of life in acute and chronic coughers. Chest 2005;127 1991-8.

23. Sekizawa K, Ujiie $Y$, Itabashi S, et al. Lack of cough reflex in aspiration pneumonia. Lancet 1990;335:1228-9.

24. Nakazawa H, Sekizawa K, Ujiie Y, et al. Risk of aspiration pneumonia in the elderly (letter). Chest 1993; 103:1636-7.

25. Katsumata U, Sekizawa K, Ebihara T, et al. Aging effects on cough reflex (letter). Chest 1995;107:290-1.

\title{
Lung alert
}

\section{Pseudomonas: is chronic infection behind acute exacer- bations in COPD?}

Approximately half of acute exacerbations of chronic obstructive pulmonary disease (AECOPD) are associated with bacterial infection, and Pseudomonas aeruginosa is increasingly recognised as an important pathogen. Up to $13 \%$ of AECOPD are associated with $P$ aeruginosa in patients with severe airflow obstruction. Whether chronic infection with $P$ aeruginosa predisposes to AECOPD is not entirely clear.

Sputum samples positive for $P$ aeruginosa taken from 13 patients with AECOPD were compared with blood samples from 10 patients with acute bacteraemia. Eight of the patients with COPD had sequential positive samples of $P$ aeruginosa at other AECOPD. Samples were molecularly typed and production of virulence factors, mutation rates and motility were investigated.

Each of the eight patients with COPD with sequential infections had established $P$ aeruginosa clones. There was no indication of transmission of these clones between patients. These strains showed aspects of the characteristic evolution of chronic $P$ aeruginosa infections seen in patients with cystic fibrosis (CF). Unsurprisingly, recurrent infections were linked with bacteria which were hypermutable and displayed increasing antibiotic resistance. When compared with the $P$ aeruginosa isolates from blood, those from the lung produced more biofilm and were less cytotoxic and motile.

The authors have shown that expression of virulence factors differs in acute and chronic $P$ aeruginosa infection. This study therefore supports others in demonstrating that $P$ aeruginosa can cause a chronic infection in COPD similar to that seen in patients with CF. Using data from CF studies may provide important information on the management of this process.

- Martı́nez-Solano L, Macia MD, Fajardo A, et al. Chronic Pseudomonas aeruginosa infection in chronic obstructive pulmonary disease. Chronic Infect Dis 2008;47:1526-33.

\author{
K Lindsay \\ Correspondence to: Ms K Lindsay, Medical Student, University College London, London, UK; k.lindsay@ucl.ac.uk
}

